\title{
Turbulent Spot Observations within a Hypervelocity Boundary Layer on a 5-degree Half-Angle Cone
}

\author{
Joseph S. Jewell ${ }^{1}$ and Nicholaus J. Parziale ${ }^{2}$ \\ California Institute of Technology, Pasadena, CA, 91125 \\ Ivett A. Leyva ${ }^{3}$ \\ Air Force Research Laboratory, Edwards AFB, CA, 93536 \\ Joseph E. Shepherd ${ }^{4}$ \\ California Institute of Technology, Pasadena, CA, 91125
}

\section{Nomenclature}

$C_{l e} \quad=\quad U_{l e} / U_{e}$ normalized turbulent spot leading edge propagation rate

$C_{m}=U_{m} / U_{e}$ normalized turbulent spot trailing edge propagation rate

$C_{t e}=U_{t e} / U_{e}$ normalized turbulent spot centroid/peak propagation rate

$M_{\mathrm{e}} \quad=$ boundary layer edge Mach number

$\dot{q} \quad=$ heat flux (transfer rate)

$\dot{q}_{L} \quad=$ laminar heat flux

$\dot{q}_{T} \quad=$ turbulent heat flux

$\operatorname{Re}_{1} \quad=$ unit Reynolds number

$\mathrm{Re}_{1 \mathrm{e}} \quad=$ boundary layer edge unit Reynolds number

$\mathrm{T}_{\mathrm{e}} \quad=$ boundary layer edge temperature

$\mathrm{T}_{\mathrm{w}} \quad=$ wall temperature

$U_{e} \quad=$ boundary layer edge velocity

$\alpha=$ turbulent spot spreading angle

\section{Introduction}

L aminar to turbulent transition is a critically important process in hypersonic vehicle design. Higher thermal loads, by half an order of magnitude or more, result from the increased heat transfer due to turbulent flow. Drag, skin friction, and other flow properties are also significantly impacted. Transition to turbulence in initially laminar boundary layers can occur along many paths. In low-speed flow under ideal conditions (quiet freestream, nominally smooth surfaces with favorable or zero pressure gradient and minimal crossflow) transition occurs over a finite distance and is associated with the creation and growth of propagating patches of turbulent flow, known as turbulent spots. Spots may be due to the breakdown of linear instabilities or induced by "bypass mechanisms" associated with nonideal effects in the flow or model. H.W. Emmons (1951) was the first to propose that laminar boundary layers break down through the convergence of spots, after observations of a water-table analogy to air flow. Spot formation has been studied extensively in subsonic flows, a recent review of past and current work on spots in incompressible flows is given by Strand and Goldstein (2011).

The first turbulent spots in a supersonic boundary layer were detected by James (1958) on free-launched projectiles using spark shadowgraphs with a conical light field, characterizing both propagation speed and growth rate for free-stream Mach numbers from 2.7 to 10. James was able to surmise that the differences were likely to be small between turbulent-spot propagation in subsonic and supersonic flow. Around the same time, Deissler and

\footnotetext{
${ }^{1}$ PhD Candidate, GALCIT, MC 205-45, Caltech. AIAA Student Member.

${ }^{2}$ PhD Candidate, GALCIT, MC 205-45, Caltech. AIAA Student Member.

${ }^{3}$ Sr. Aerospace Engineer, Air Force Research Laboratory. AIAA Senior Member.

${ }^{4}$ Professor, GALCIT, MC 105-50, Caltech. AIAA Senior Member.
} 

HYPERSONICS

Loeffler (1958) studied supersonic transition on a flat plate. Since then, a number of studies of spots in supersonic and hypersonic flows have been carried out, with reviews given by Fiala et al. (2006) and Mee (2002).

\section{Recent Work on Supersonic Flows}

Clark (1993) and Clark et al. (1994) studied the propagation of naturally-occurring turbulent spots in turbinerepresentative flows from Mach 0.24 to Mach 1.86 using thin-film heat transfer gauges to track individual spots. Clark characterized turbulent spot leading-edge, trailing-edge, and "mean" or centroid velocities, and also measured the spreading angle at several Mach numbers in this range. Clark also examined the propagation of turbulent spots in mild and strong pressure gradients both favorable and adverse.

Hofeldt (1996) and Hofeldt et al. (1998) also studied spots in flows from Mach 0.24 to Mach 1.86 using thinfilm heat transfer gauges, examining the effect of gas-to-wall temperature ratios as well as the "overhang" regionthe turbulent spot's spatial extent in the downstream direction is greater further from the plate and observing "becalmed" regions behind turbulent spots. Hofeldt was able to show that the becalmed region behind a turbulent spot is in fact consistent with the re-establishment of a laminar boundary layer.

Mee and Goyne (1996) performed experiments to detect turbulent spots on a flat plate in free-piston shock tunnel flows of Mach 5.6 to 6.1 at low, mid-range, and high unit Reynolds numbers $\left(\operatorname{Re}_{\mathrm{x}}\right.$ between $1.6 \times 10^{6} \mathrm{~m}^{-1}$ and $4.9 \times$ $10^{6} \mathrm{~m}^{-1}$ ) using thin-film heat transfer gauges. They were able to detect turbulent spot activity and measure intermittency, and recommended further tests to measure convection speeds and spreading rate. Mee (2001) and Mee (2002), using the same facility as Mee and Goyne (1996) with new instrumentation, measured the effect of using 2 mm-high boundary layer "trips" behind the leading edge of a flat plate in Mach 5.5 to Mach 6.3 free-piston shock tunnel flow and found them to be capable of advancing the transition location. Mee measured a spot growth angle of $3.5^{\circ} \pm 0.5^{\circ}$.

Fiala et al. (2006) measured turbulent spots progressing on a blunt cylindrical body with spherical nose in hypersonic flow (Mach 8.9 free stream; Mach 3.74 at the edge of the boundary layer) using a series of thin-film heat transfer gauges. They were able to detect clear turbulent spot activity and measure intermittency by comparing heat transfer time histories from axial gauges in the intermittent region of the body, and also visualize the passing signals from individual spots with a circumferential array of gauges. Computational studies of spot propagation in supersonic flows have been carried out by Chong and Zhong (2005), Krishan and Sandham (2006), and Jocksch and Kleiser (2008). Sivasubramanian and Fasel (2010) have carried out DNS of turbulent spot evolution on a cone in Mach 6 cold flow and observed the breakdown of two-dimensional second mode disturbances into a threedimensional wave packet or spot. Selected results of experiments and computations are given in Table 2.
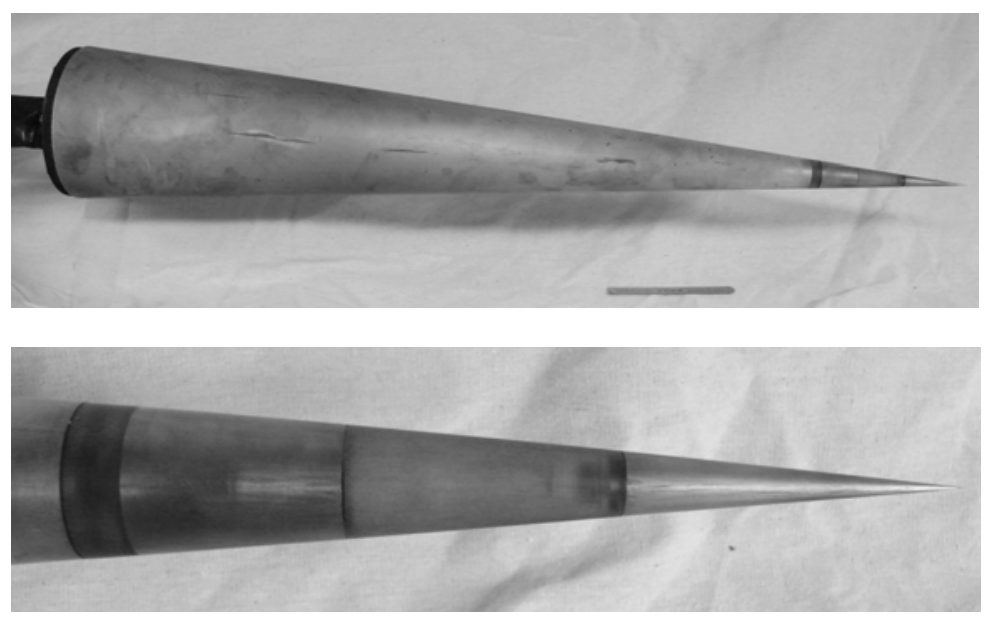

Figure 1. Top: Aluminum cone, $1 \mathrm{~m}$ in length, instrumented with 80 thermocouples in 20 rows. Bottom, from right to left: molybdenum tip, plastic holder with 316L stainless steel 10 micron porous section, aluminum cone body.
Rasheed (2001). Previous studies in T5 have mainly used these gauges to measure mean heat transfer as an indicator

\section{Experiment}

The facility used in all experiments for the current study is the T5 hypervelocity reflected shock tunnel; see Hornung (1992) and Hornung and Belanger (1990). The model is a 5 degree half-angle aluminum cone similar to that used in a number of previous experimental studies in $\mathrm{T} 5$. The models is $1 \mathrm{~m}$ in length, and is composed of three sections: a sharp tip fabricated of molybdenum, a mid-section containing a porous gas-injector section, and the main body instrumented with a total of 80 thermocouples in evenly spaced rows $38 \mathrm{~mm}$ apart at 20 lengthwise locations between $220.9 \mathrm{~mm}$ and $942.0 \mathrm{~mm}$ from the cone tip. These thermocouples have a response time (Marineau and Hornung 2009) on the order of a few microseconds and have been successfully used for boundary layer transition location in Adam (1997) and

American Institute of Aeronautics and Astronautics Distribution A: Approved for public release; distribution unlimited. 

HYPERSONICS
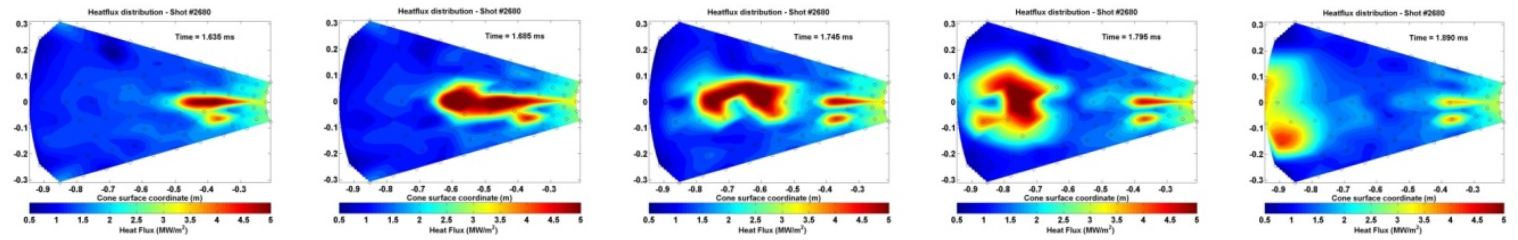

Figure 2. Time-resolved heat transfer rate plots of the developed cone surface. In these frames from a heat flux "movie", a turbulent spot can be seen growing as it propagates down the surface of the cone. Flow in each image goes from right to left.

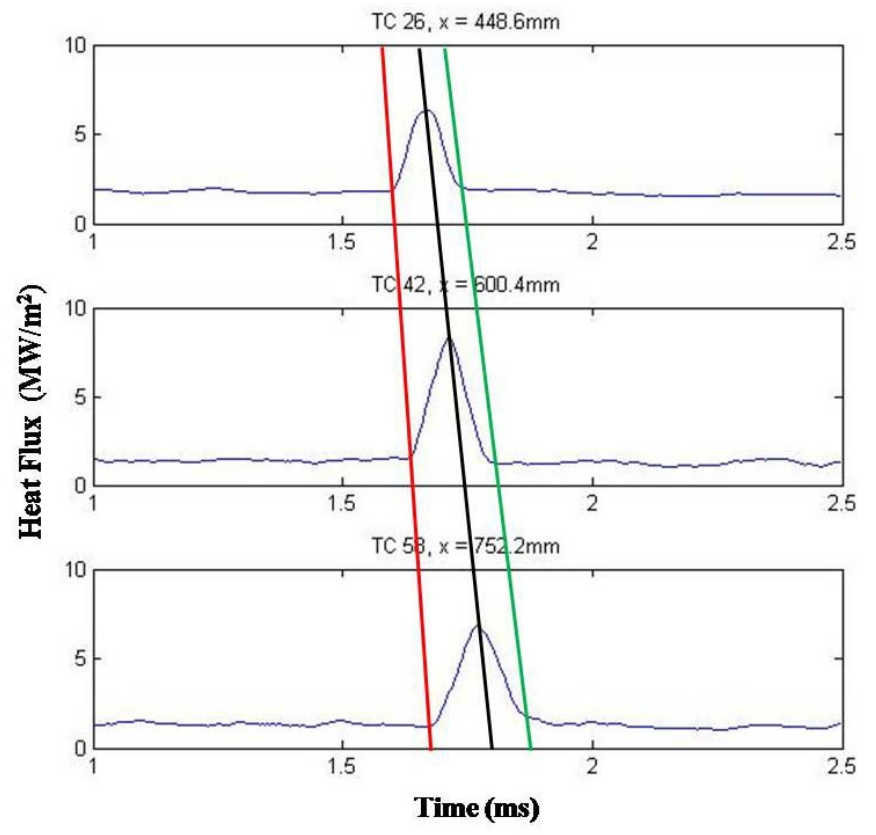

Figure 3. Smoothed heat transfer traces from three colinear thermocouples, at $x$-displacements from the cone tip of $448.6 \mathrm{~mm}, 600.4 \mathrm{~mm}$, and $752.2 \mathrm{~mm}$, respectively, under the propagating spot depicted in Figure 2. The spot's leading edge (red), centroid (black), and trailing edge (green) velocities may be calculated from the signals. of average laminar to turbulent flow transition location. In the present study, a denser array of the gauges was used compared to the past studies and the high-speed data recordings were utilized more fully in order to visualize and quantify turbulence spot motion.

For simplicity and comparison with previous experimental and computational results, the cone axis was aligned with the tunnel axis as closely as possible to a zero degree angle of incidence to the flow. A photograph of the cone model is shown in Figure 1. The porous injector section is $4.13 \mathrm{~cm}$ in length and consists of sintered 316L stainless steel, with an average pore size of 10 microns. A detail view of the tip and porous injector section is shown in the bottom of Figure 1. Although the injector section was installed during the present tests, no injection was used. The section has been shown not to trip the boundary layer when gas is not injected.

A method of presenting time- and spatiallyresolved heat flux data has been developed and implemented, which allows the presentation of a "movie" of heat flux over the entire instrumented surface of the cone during the test time (see Figure 2). A similar method has allowed the observation of turbulent "spots" observed in lower-speed flow (Clark 1994). Figure 3, depicts the results from shot 2680, and the trajectories shown indicate how we have characterized spots by leading edge, trailing edge and centroid (peak) velocity. Measurements for six such spots, at a Mach number of about 5.1, are presented in Table 1 as fractions of the respective boundary layer edge velocities. The present results may be compared with other experimental and computational supersonic and hypersonic results at similar and disparate boundary layer edge conditions, presented in the same format in Table 2. The non-dimensionalized average heat flux gauge signals are plotted (Figures 4-9) for each of these six runs as Stanton number versus Reynolds number based on the distance of the gauge from the tip of the cone. In each case, the boundary layer is on average laminar over the majority of the length of cone, with some cases showing incipient transition near the end of the cone so that the spots we are observing are propagating as isolated turbulent patches within the surrounding laminar flow. The initiating events for these spots are unknown but may be due to the nonlinear breakdown of second mode instabilities, which have recently been observed within similar transitional boundary layers in T5 using a recently developed optical method for observing low-amplitude, high-frequency density fluctuations (Parziale et al 2012). 
42nd AIAA Fluid Dynamics Conference and Exhibit, 25-28 June 2012, New Orleans, Louisiana HYPERSONICS

\begin{tabular}{|c|c|c|c|c|c|c|}
\hline Shot & $\mathbf{2 6 4 5}$ & $\mathbf{2 6 5 4}$ & $\mathbf{2 6 8 0}$ & $\mathbf{2 7 0 2}$ & $\mathbf{2 7 0 6}$ & $\mathbf{2 7 1 8}$ \\
\hline $\boldsymbol{H}_{\boldsymbol{0}}[\mathrm{MJ} / \mathrm{kg}]$ & 10.26 & 10.68 & 9.48 & 8.74 & 9.53 & 10.44 \\
\hline $\boldsymbol{P}_{\boldsymbol{0}}[\mathrm{MPa}]$ & 54.3 & 74.1 & 71.2 & 49.9 & 49.0 & 70.1 \\
\hline $\boldsymbol{M}_{\boldsymbol{e}}$ & 5.07 & 5.04 & 5.11 & 5.20 & 5.11 & 5.04 \\
\hline $\boldsymbol{u}_{\boldsymbol{e}}[\mathrm{m} / \mathrm{s}]$ & 3995 & 4087 & 3875 & 3732 & 3871 & 4034 \\
\hline $\mathbf{R e}_{\boldsymbol{l}}[1 / \mathrm{m}]$ & $5.18 \times 10^{6}$ & $6.63 \times 10^{6}$ & $7.42 \times 10^{6}$ & $5.72 \times 10^{6}$ & $5.15 \times 10^{6}$ & $6.46 \times 10^{6}$ \\
\hline $\boldsymbol{T}_{\boldsymbol{w}} / \boldsymbol{T}_{\boldsymbol{e}}$ & 0.180 & 0.169 & 0.195 & 0.219 & 0.196 & 0.174 \\
\hline $\boldsymbol{C}_{\boldsymbol{l} \boldsymbol{e}}$ & $0.92 \pm 0.04$ & $0.93 \pm 0.08$ & $0.96 \pm 0.07$ & $0.92 \pm 0.03$ & $0.79 \pm 0.04$ & $0.87 \pm 0.04$ \\
\hline $\boldsymbol{C}_{\boldsymbol{m}}$ & $0.82 \pm 0.04$ & $0.77 \pm 0.08$ & $0.78 \pm 0.07$ & $0.58 \pm 0.03$ & $0.69 \pm 0.04$ & $0.88 \pm 0.04$ \\
\hline $\boldsymbol{C}_{\boldsymbol{t} \boldsymbol{e}}$ & $0.69 \pm 0.04$ & $0.56 \pm 0.08$ & $0.55 \pm 0.07$ & $0.50 \pm 0.03$ & $0.57 \pm 0.04$ & $0.77 \pm 0.04$ \\
\hline
\end{tabular}

Table 1. Results for turbulent spot propagation rates, presented in terms of the ratio of measured spot leading edge $\left(C_{l e}\right)$, centroid $\left(C_{m}\right)$, and trailing edge $\left(C_{t e}\right)$ velocities to the calculated velocity at the boundary layer edge, $u_{e}$. The reservoir enthalpy and reservoir pressure at the end of the shock tube are also provided. Free stream species and boundary layer edge conditions are calculated with an expansion through a contoured nozzle with area ratio 100, followed by a conical shock emanating from the tip of the cone.

\begin{tabular}{|c|c|c|c|c|c|c|c|c|}
\hline & $\begin{array}{c}\mathrm{Z} \& \mathrm{H} \\
1996\end{array}$ & $\begin{array}{l}\text { Fiala } \\
2006\end{array}$ & $\begin{array}{l}\text { Mee } \\
2002\end{array}$ & $\begin{array}{c}\text { Clark } \\
1994\end{array}$ & $\begin{array}{c}\text { K \& S } \\
2006\end{array}$ & $\begin{array}{c}\mathrm{J} \& \mathrm{~K} \\
2008\end{array}$ & $\begin{array}{c}\text { J \& K } \\
2008\end{array}$ & $\begin{array}{c}\text { S \& F } \\
2010\end{array}$ \\
\hline Type & Exp. & Exp. & Exp. & Exp. & Comp. & Comp. & Comp. & Comp. \\
\hline$M_{e}$ & $8.02^{b}$ & 3.74 & 6.1 & 1.86 & 6 & 5 & 5 & 6 \\
\hline $\boldsymbol{u}_{\boldsymbol{e}}[\mathrm{m} / \mathrm{s}]$ & $\mathrm{a}$ & $1300^{b}$ & 3370 & $580^{b}$ & $\mathrm{a}$ & $\mathrm{a}$ & $\mathrm{a}$ & 875 \\
\hline $\mathbf{R e}_{1 e}[1 / \mathrm{m}]$ & $\mathrm{a}$ & $2.69 \times 10^{6}$ & $4.9 \times 10^{6}$ & $16.0 \times 10^{6}$ & $\mathrm{a}$ & $\mathrm{a}$ & $\mathrm{a}$ & $11.0 \times 10^{6}$ \\
\hline$T_{w} / T_{e}$ & $4.38^{b}$ & $0.97^{b}$ & $0.371^{\mathrm{b}}$ & $1.23^{b}$ & 7.00 & 5.19 & 1.00 & 5.7 \\
\hline$C_{l e}$ & 0.98 & 0.81 & $0.90 \pm 0.10$ & $0.83 \pm 0.04$ & 0.89 & 0.96 & 0.89 & 0.91 \\
\hline$C_{m}$ & - & - & - & $0.64 \pm 0.02$ & $0.76^{\mathrm{c}}$ & - & - & - \\
\hline$C_{t e}$ & 0.68 & 0.40 & $0.50 \pm 0.10$ & $0.53 \pm 0.02$ & 0.53 & 0.54 & 0.23 & 0.79 \\
\hline \multicolumn{9}{|c|}{$\begin{array}{l}\text { a: value not reported } \\
\text { b: calculated from other reported values } \\
\text { c: spot "wing tip" convection velocity }\end{array}$} \\
\hline
\end{tabular}

Table 2. The present experimental (Mach 5 cone) results may be compared with other supersonic and hypersonic experiments (Zanchetta and Hillier 1996, Fiala et al. 2006, Mee 1996, and Clark et al. 1994) and computations (Krishnan and Sandham 2006, two results from Jocksch and Kleiser 2008, and one from Sivasubramanian and Fasel 2010) reported for a range of conditions.

At lower Mach numbers, such as the results of Clark et al. (1994), the subsonic (first) mode is the dominant linear boundary layer instability mechanism. At hypersonic Mach numbers $(>4)$, instabilities in the second (Mack) acoustic mode dominate the boundary layer transition mechanism. For cold-wall hypervelocity flow with a hot freestream, which is characteristic of high-enthalpy shock tunnels like T5 and T4, the first mode is expected to be damped and the higher inviscid modes are amplified, so that the second mode would be expected to be the only mechanism of linear instability. The present results are thus most directly comparable, in terms of Mach number and wall temperature ratio, to those of Mee (2002), and indeed are largely within the uncertainty range of Mee's measurements. 
42nd AIAA Fluid Dynamics Conference and Exhibit, 25-28 June 2012, New Orleans, Louisiana HYPERSONICS

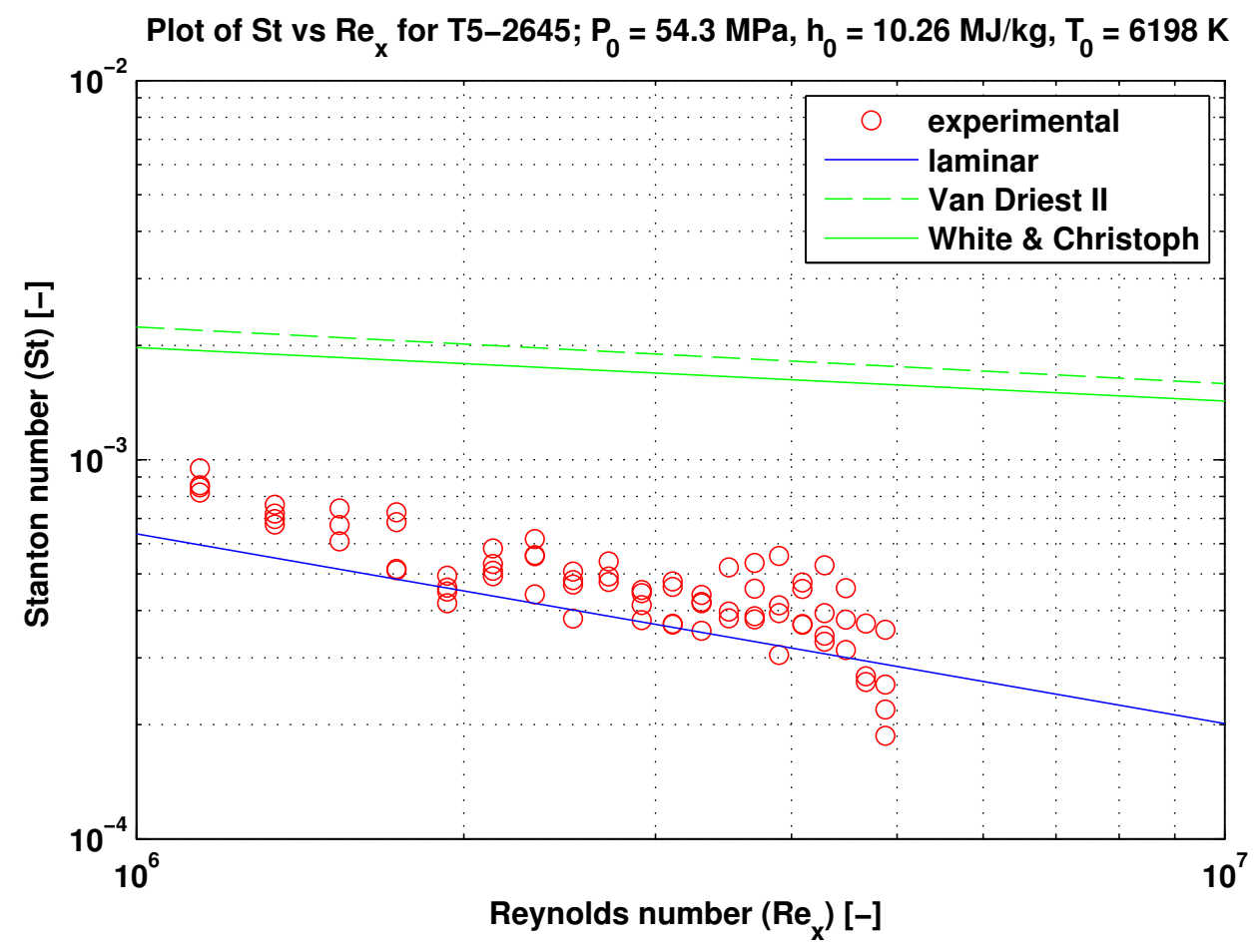

Figure 4. Stanton number versus Reynolds number plot for test 2645. See Table 1 for edge conditions.

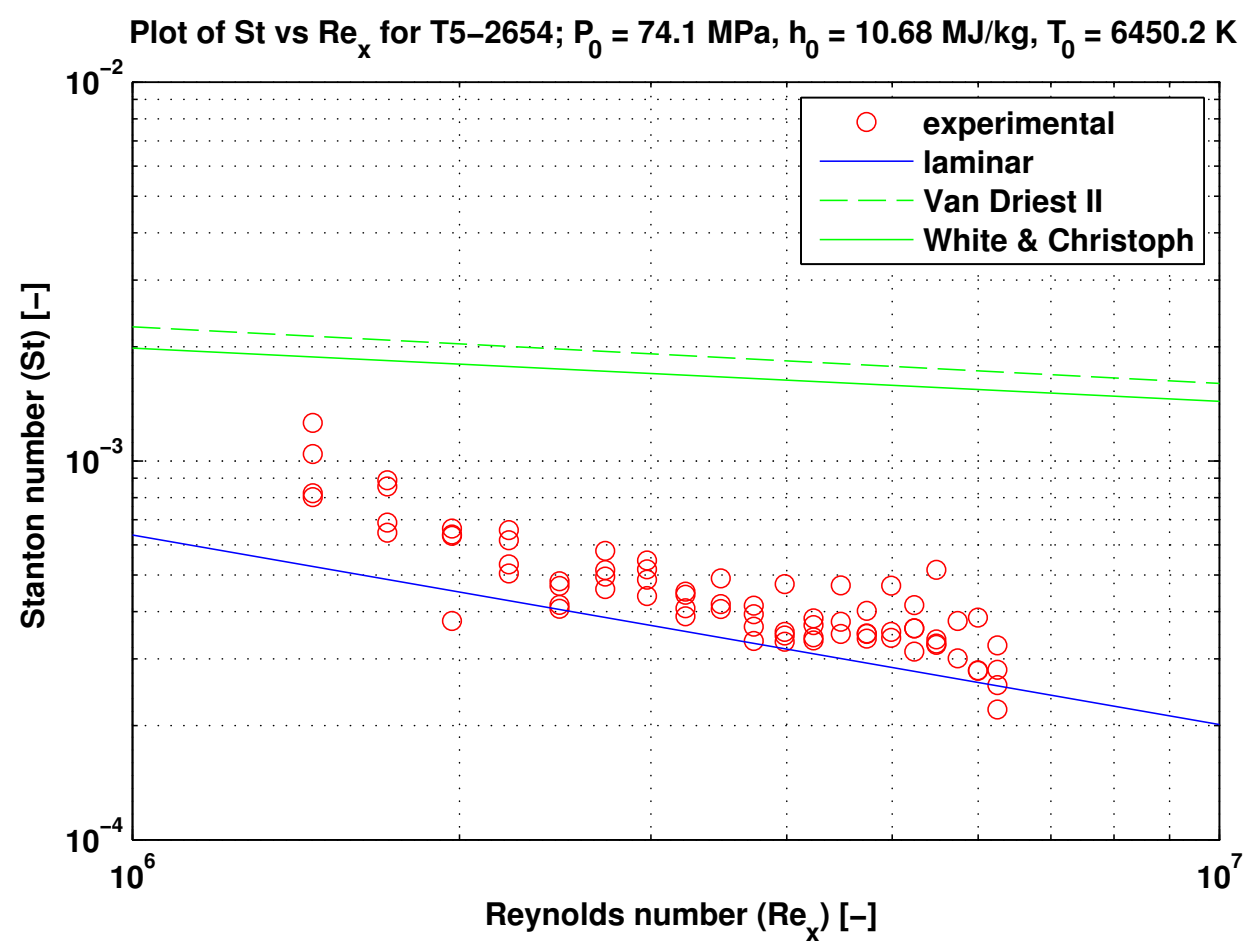

Figure 5. Stanton number versus Reynolds number plot for test 2654. See Table 1 for edge conditions. 
42nd AIAA Fluid Dynamics Conference and Exhibit, 25-28 June 2012, New Orleans, Louisiana HYPERSONICS

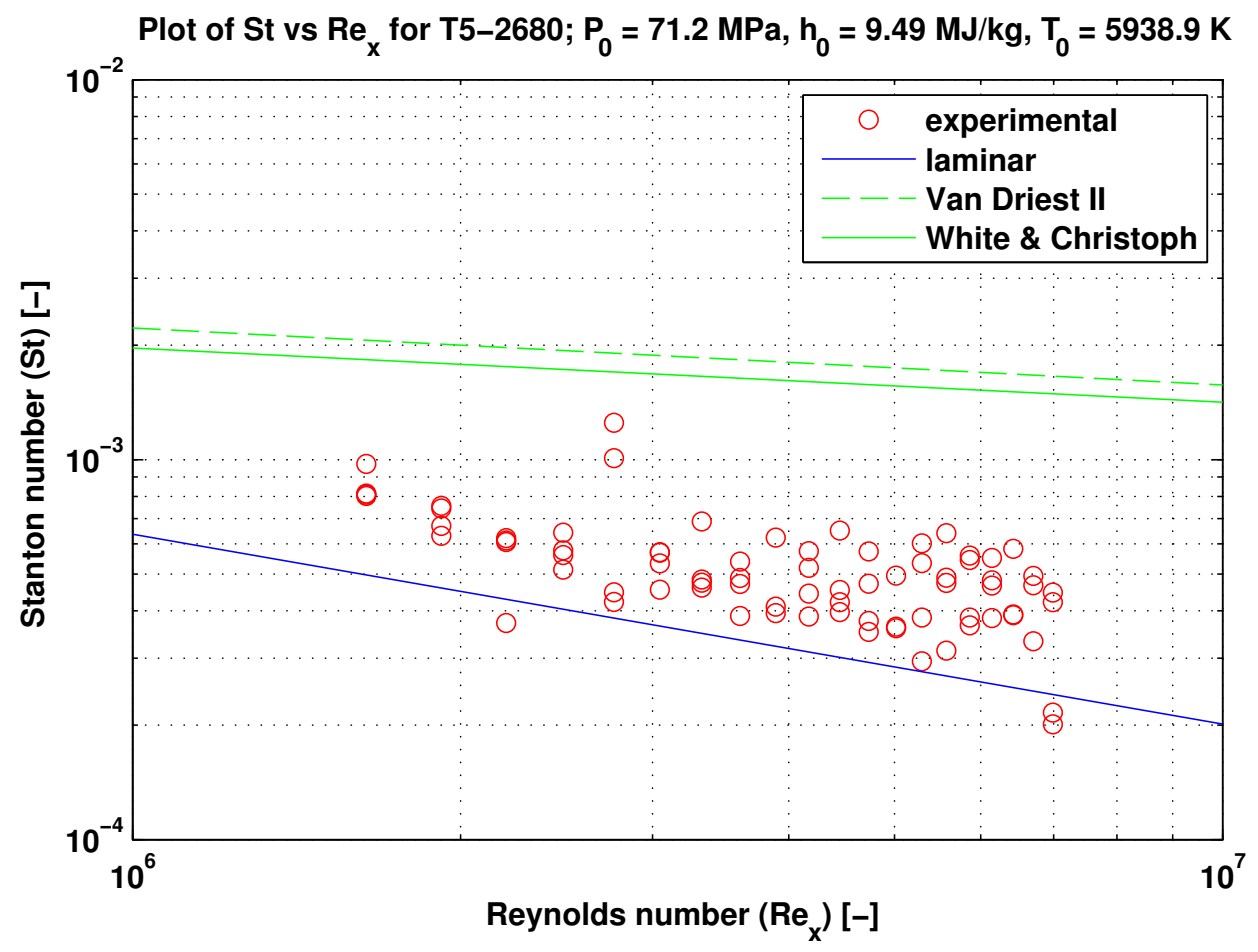

Figure 6. Stanton number versus Reynolds number plot for test 2680. See Table 1 for edge conditions.

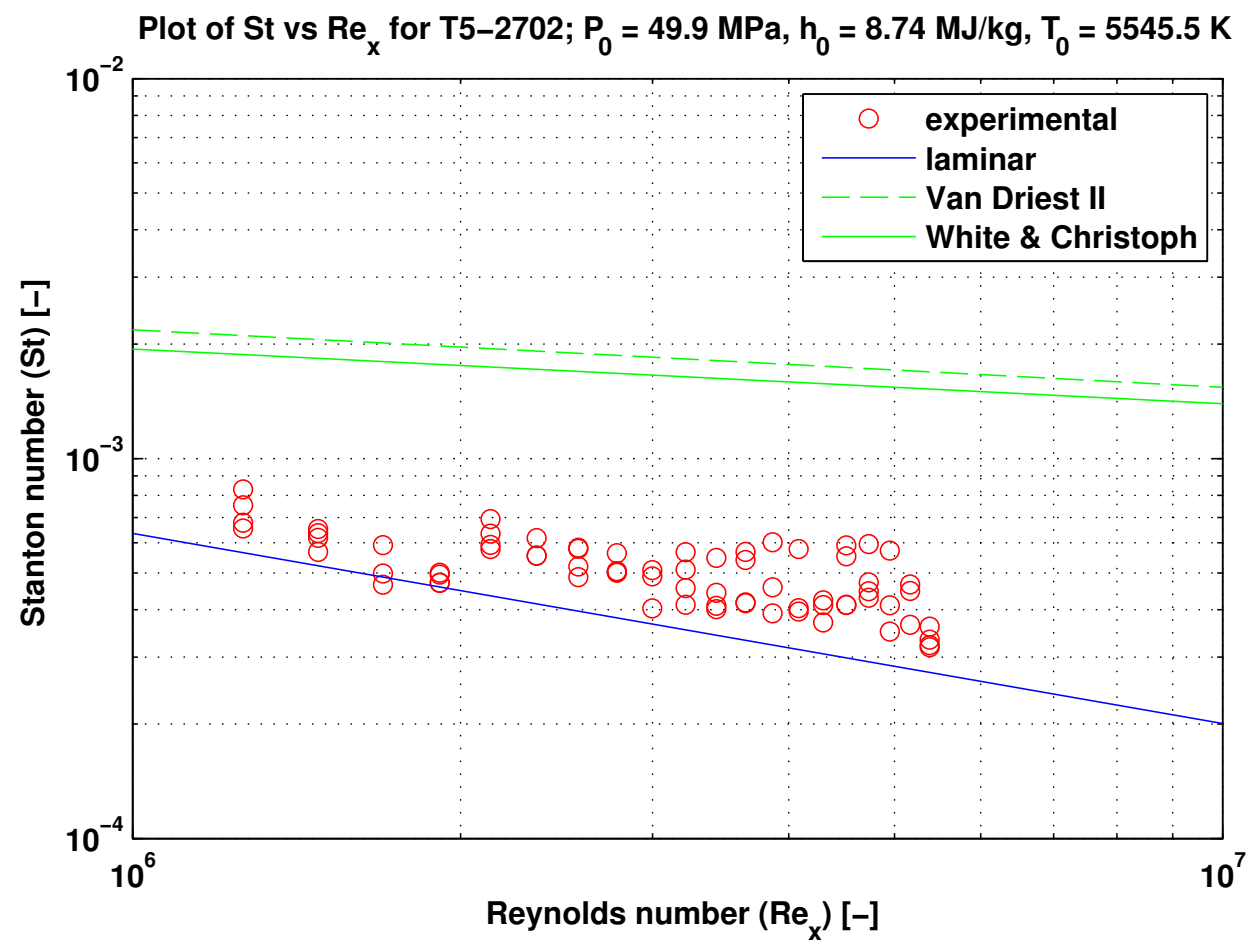

Figure 7. Stanton number versus Reynolds number plot for test 2702. See Table 1 for edge conditions. 
42nd AIAA Fluid Dynamics Conference and Exhibit, 25-28 June 2012, New Orleans, Louisiana HYPERSONICS

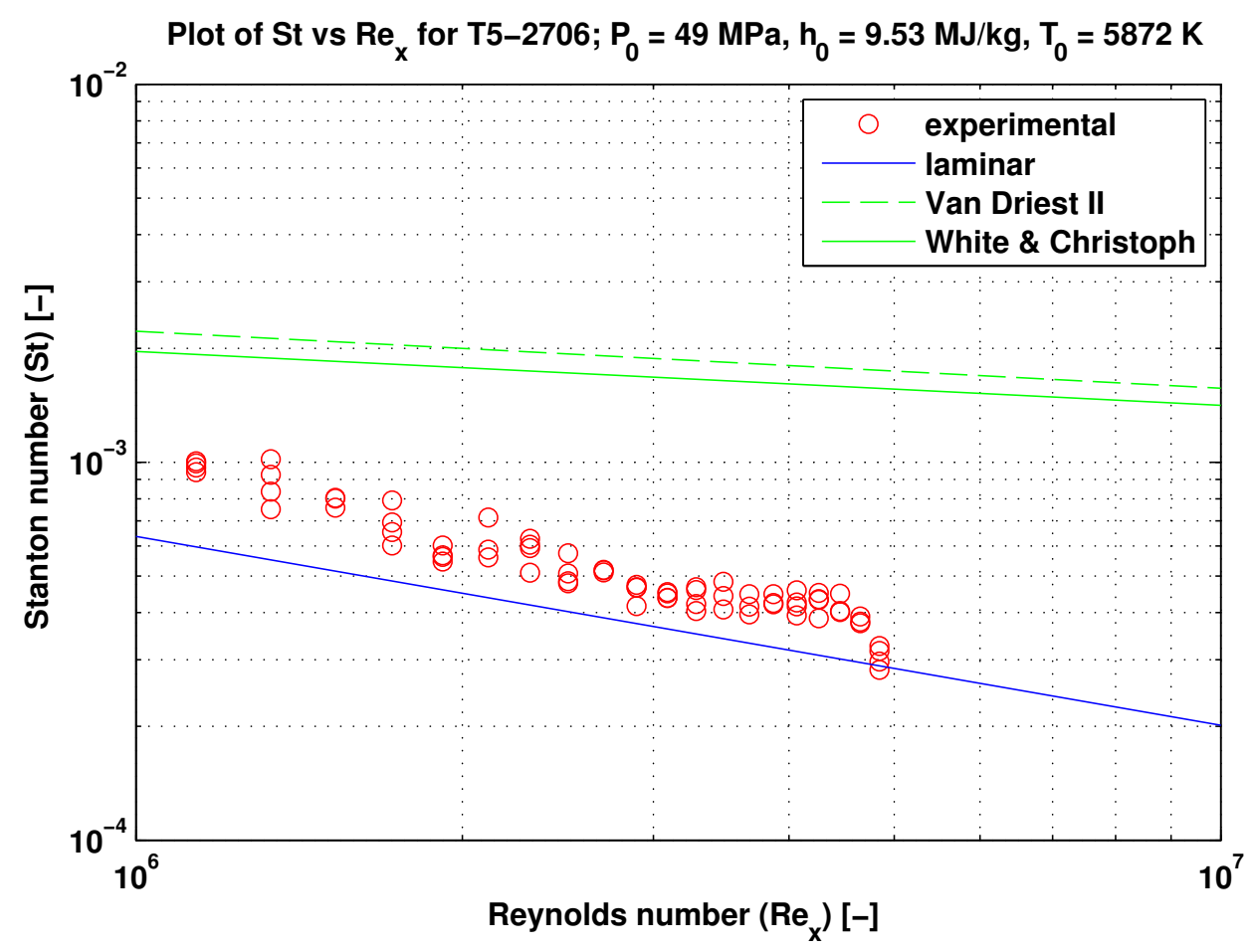

Figure 8. Stanton number versus Reynolds number plot for test 2706. See Table 1 for edge conditions.

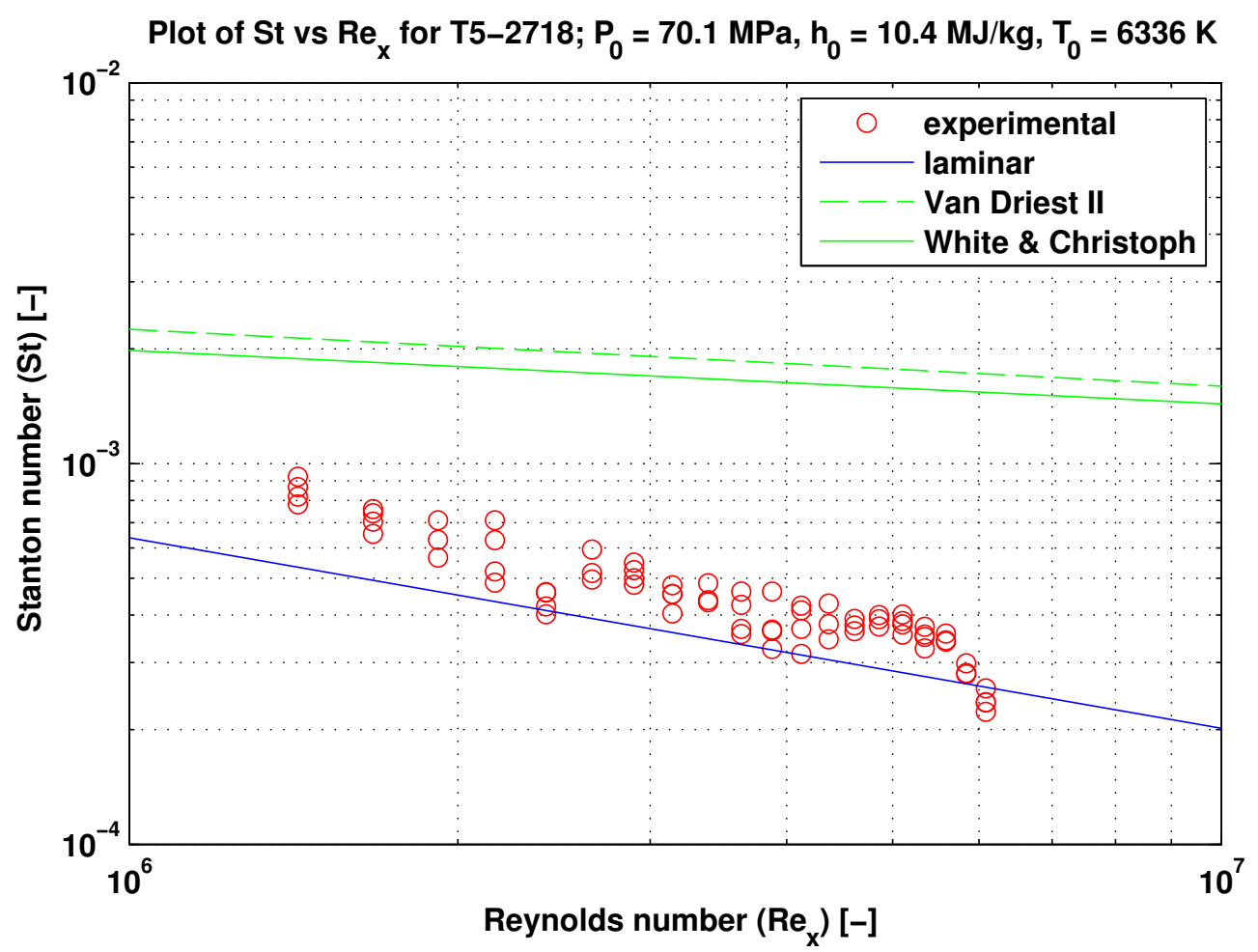

Figure 9. Stanton number versus Reynolds number plot for test 2645. See Table 1 for edge conditions. 


\section{Conclusion}

Time- and spatially-resolved heat transfer traces in a high-enthalpy hypervelocity flow on a 5-degree half angle cone are measured with thermocouples. Turbulent spots are observed propagating in both heat transfer traces and heat flux "movies" of the developed cone surface. These observations are used to calculate turbulent spot convection rates, which are compared with previous experimental and computational results. Although the present results were obtained at different conditions from past experiments, the normalized spot propagation results for Mach 5 flow appear to be generally consistent with past supersonic and hypersonic experiments, as well as with the computational results. However, all available computational results of spot propagation in hypersonic flow in the present literature survey simulated much higher wall temperature ratios $T_{w} / T_{e}$ than actually occur in reflected shock tunnel experiments (see Tables 1 and 2). The computations of Sivasubramanian and Fasel (2010) are most representative of the present conditions and their spot propagation speeds are reasonably consistent with our experimental results. However, the flow conditions in all of these simulations are essentially nonreactive (cold flow with frozen composition) and the ratios of freestream to wall temperature in the simulations are far from our experimental conditions. The flow conditions in these $\mathrm{T} 5$ tests are designed to simulate hypervelocity atmospheric flight and the flow over the model is hot, partially-dissociated air with some amount of chemical and vibrational nonequilibrium due to the rapid expansion process in the nozzle. Because of the sparse number and nature of the thermocouple data, there is substantial uncertainty in defining the precise leading and trailing edges of the spot. Taking the results of all six examples together, the putative leading edge nominally propagates at about $0.90 U e$, the centroid at $0.75 \mathrm{Ue}$, and the trailing edge at $0.60 \mathrm{Ue}$, with an estimated uncertainty of $\pm 0.05 \mathrm{Ue}$. While the design of the experiment precludes precise measurement of spot spreading angle $\alpha$, preliminary bounding values for this parameter have been obtained. For example, for shot 2654, we estimate $2^{\circ}<\alpha<13^{\circ}$, which brackets the reported value of $3.5^{\circ} \pm 0.5^{\circ}$ of Mee (2002). More precise measurements of propagation speed and spreading angle would be possible with the addition of thermocouples in a more circumferentially dense pattern.

\section{Acknowledgments}

The authors thank Mr. Bahram Valiferdowsi for his work with design, fabrication, and maintenance, and Prof. Hans Hornung for his advice and support. This project was sponsored by the Air Force Office of Scientific Research under award number FA9550-10-1-0491 and the NASA/AFOSR National Center for Hypersonic Research. The views expressed herein are those of the authors and should not be interpreted as necessarily representing the official policies or endorsements, either expressed or implied, of AFOSR or the U.S. Government.

\section{References}

Adam, P.H., Enthlapy Effects on Hypervelocity Boundary Layers. PhD Thesis, California Institute of Technology, Pasadena, CA, 1997. See also Adam, P.H. and Hornung, H.G. "Enthalpy Effects on Hypervelocity Boundary-Layer Transition: Ground Test and Flight Data” J. Spacecraft Rockets, Vol. 34(5), 614-619, 1997.

Chong, T.P. and Zhong, S. “On the Three-Dimensional Structure of Turbulent Spots,” Journal of Turbomachinery, Vol. 127, June 2005, pp. 545-551.

Clark, J.P., A Study of Turbulent-Spot Propagation in Turbine-Representative Flows, D.Phil Thesis, Department of Engineering Science, University of Oxford, 1993.

Clark, J.P., Jones, T.V., and LaGraff, J.E., "On the Propagation of Naturally-Occurring Turbulent Spots," Journal of Engineering Mathematics, Vol. 28, 1994, pp. 1-19.

Clark, J.P., Magari, P.J., and Jones, T.V., On the Distribution of the Heat-Transfer Coefficient in Turbulent and 'Transitional' Wedges, Department of Engineering Science, Oxford University, Parks Road, Oxford OX1 3PJ, United Kingdom, 1993.

Deissler, H.G. and Loeffler, A.L. "Analysis of Turbulent Flow and Heat Transfer on a Flat Plate at High Mach Numbers with Variable Fluid Properties.” NACA TN 4262, Washington, April 1958.

Emmons, H.W., "The Laminar-Turbulent Transition in a Boundary Layer-Part I," Journal of the Aeronautical Sciences, Vol. 18, No. 7, 1951, pp. 490-498.

American Institute of Aeronautics and Astronautics Distribution A: Approved for public release; distribution unlimited. 
Fiala, A., Hillier, R., Mallinson, S.G. and Wijesinghe, H.S., "Heat transfer measurement of turbulent spots in a hypersonic blunt-body boundary layer.” Journal of Fluid Mechanics, Vol. 555, 2006, pp. 81-111.

Hofeldt Jr., A.J., The Investigation of Naturally-Occurring Turbulent Spots Using Thin-Film Gauges, D.Phil Thesis, Department of Engineering Science, University of Oxford, 1996.

Hofeldt Jr., A.J., Jones, TV., Clark, J.P., and LaGraff, J.E., The Becalmed Region of Naturally-Occurring Turbulent Spots, Department of Engineering Science, Oxford University, Parks Road, Oxford OX1 3PJ, United Kingdom, 1998.

Hornung, H.G. and Belanger, J. "Role and techniques of ground testing simulation of flows up to orbital speeds.” 1990. AIAA 90-1377.

Hornung, H.G. "Performance data of the new free-piston shock tunnel at GALCIT.” 1992. AIAA 92-3943.

James, C.S., "Observation of turbulent-burst geometry and growth in supersonic flow,” NACA TN 4235, 1958.

Jocksch, A. and Kleiser, L. "Growth of turbulent spots in high-speed boundary layers on a flat plate." International Journal of Heat and Fluid Flow, Vol. 29, 2008, 1543-1557.

Krishnan, L. and Sandham, N.D. "Effect of Mach number on the structure of turbulent spots.” Journal of Fluid Mechanics, Vol. 556, 2006, pp. 225-234.

Marineau, E., and Hornung, H., "Modeling and Calibration of Fast-Response Coaxial Heat Flux Gages," AIAA Paper 2009-

737, $47^{\text {th }}$ AIAA Aerospace Sciences Meeting, Orlando, FL, Jan 2009

Mee, D.J., "Boundary Layer Transition Measurements in Hypervelocity Flows in a Shock Tunnel," AIAA Journal, Vol. 40, No. 8, August 2002, pp. 1542-1548.

Mee, D.J., Transition Measurements on a 5 Degree Cone in the T4 Shock Tunnel, University of Queensland, Department of Mechanical Engineering, Research Report Number 2001-2.

Mee, D.J. and Goyne, C.P., "Turbulent spots in boundary layers in a free-piston shock tunnel flow", Proceedings of the 20th International Symposium on Shock Waves, Pasadena, USA, 24-28 July 1995. Edited by B. Sturtevant, J.E. Shepherd and H.G. Hornung. World Scientific, Singapore, 1996, pp. 771-776.

Parziale, N., Shepherd, J.E., and Hornung, H.G. "Reflected Shock Tunnel Noise Measurement by Focused Differential Interferometry” 42nd AIAA Fluid Dynamics Conference and Exhibit, June, 2012, New Orleans, Louisiana.

Rasheed, A., Passive hypervelocity boundary layer control using an acoustically absortive surface. PhD Thesis, California Institute of Technology, Pasadena, CA, 2001. See also Rasheed, A., Hornung, H.G., Fedorov, A.V., and Malmouth, N.D. "Experiments on passive hypervelocity boundary-layer control using an ultrasonically absorptive surface” AIAA J., Vol. 40(3), 481-489, 2002.

Strand, J.S. and Goldstein, D.B. "Direct numerical simulations of riblets toconstrain the growth of turbulent spots”, J. Fluid Mech. (2011), vol. 668, pp. 267-292

Sivasubramanian, J. and Fasel, H. F. "Dierct Numerical Simulation of a Turbulent Spot in a Cone Boundary Layer at Mach 6”. AIAA $40^{\text {th }}$ Fluid Dynamics Conference, June 28-July 1, 2010. AIAA 2010-4599.

Zanchetta, M. and Hillier, R. "Boundary Layer Transition on Slender Blunt Cones at Hypersonic Speeds.” Proceedings of the 20th International Symposium on Shock Waves, 1996, pp. 699-704.

American Institute of Aeronautics and Astronautics Distribution A: Approved for public release; distribution unlimited. 